\title{
Preparation and in vitro characterization of laminarin based hydrogels
}

\author{
Sıla TÜMEN ERDEN ${ }^{1}$ (D), Ceyda EKENTOK ATICI ${ }^{2}$ (D), Birnur CÖMEZ ${ }^{2}$ (D), Ali Demir SEZER ${ }^{2}$ * (D) \\ 1 Dem Pharmaceuticals, Research and Development Department, İstanbul, Turkey. \\ 2 Department of Pharmaceutical Biotechnology, Faculty of Pharmacy, Marmara University, M.Ü. Recep Tayyip \\ Erdoğan Külliyesi, Başıüyük Yolu, 34854 4/A, Başıüyük, İstanbul, Turkey. \\ * Corresponding Author. E-mail: adsezer@marmara.edu.tr (A.D.S.); Tel. +90-216-777 5447.
}

Received: 23 February 2021 / Revised: 02 March 2021 / Accepted: 03 March 2021

\begin{abstract}
Hydrogels are one of the most effective pharmaceutical forms because of several advantages in the treatment of burn and wound healings. Laminarin is a storage polysaccharide derived from brown algae and member of the 1-3- $\beta$-D-glucan family. It is a heparin-like molecule and plays role in hemostasis, regulation of cell growth and regeneration. Also, indirectly functional in neovascularization. In addition, accelerates the formation of fibroblast activity and re-epithelization. Aim of this study is prepare laminarin hydrogels and evaluate the in vitro characteristics of hydrogels for use in various wounds. For this purpose, different hydrogel formulations prepared and examined, and evaluated by water absorption capacity, viscosity, rheological and mechanical properties and bioadhesion. It was observed that hydrogels prepared with laminarin are an ideal wound dressing as expected.
\end{abstract}

KEYWORDS: Hydrogel; laminarin; carboxymethylcellulose; polyvinylpyrrolidone; wound healing.

\section{INTRODUCTION}

The term hydrogel is a combination of the words hydro (water) and gel and is used to refer to aqueous gel or more precisely, three-dimensional polymer networks that swell without dissolving in water [1]. Hydrogels have attracted great attention due to their special properties such as swelling in aqueous media, sensitivity to $\mathrm{pH}$, temperature or other stimulants [2]. Up to date, different types of hydrogels have been extensively investigated as drug delivery systems [3,4]. In terms of ionic charges in the polymer network, hydrogels are classified as anionic, cationic, neutral and ampholytic hydrogels. Hydrogels can be synthesized by a variety of techniques. Physical crosslinking, chemical crosslinking, polymerization grafting and radiation crosslinking have traditionally been used to prepare hydrogels [2].

While hydrogels form an ideal covering material in the treatment of wounds and burns caused by various reasons and protect the injured area from external factors, they increase cellular proliferation, scar formation, and shorten the treatment process of the patient with the agents they carry [5]. In addition to natural biological cover materials, cover materials prepared with semi-synthetic polymers are among the cover materials that have been developed and presented to treatment commercially. Hydrogels prepared with this type of polymers compared to other topically applied systems in wound treatment is advantageous in that it is biocompatible, has minimal toxicity and immunogenicity. In addition, the use of biological or synthetic active substances used in the treatment of burns and wounds with these polymers provides an advantage to hydrogels [6].

Laminarin is a biopolymer obtained from brown seaweeds, the main core of which is $\beta(1 \rightarrow 3)$ glucans by making $\beta(1 \rightarrow 6)$ bonds among themselves [7]. Branching, polymerization degrees and $(1,3)$ - and $(1,6)$-glycosidic bond ratios of laminarins obtained from different algae can vary [8]. It has been reported that laminarin strengthens the immune system and has antimicrobial and antitumor activities [9]. It is also known to activate these cells by binding to the receptors of immune system cells such as macrophages, neutrophils and natural killer cells. The binding of laminarin to the receptors of these cells triggers phagocytosis, respiratory burst capacity, and secretion of cytokines such as TNF- $\alpha$ and IL-1 [10]. It is known that laminarin accelerates fibroblast migration and provides re-epithelization, as well as hemostasis [7].

How to cite this article: Tümen Erden S, Ekentok Atıcı C, Çömez B, Sezer AD. Preparation and in vitro characterization of laminarin based hydrogels. J Res Pharm. 2021; 25(2): 164-172. 
Carboxymethyl cellulose (CMC) is a polymer formed by the reaction of cellulose derived sodium hydroxide and chloroacetic acid. It is obtained by the replacement of hydrogen atoms in the hydroxyl groups of cellulose with carboxymethyl units and is generally used as sodium salt [11]. The most important feature of $\mathrm{CMC}$ is that it creates viscosity. At the same time, carboxymethyl cellulose provides an advantage among all polysaccharides as it is easily accessible and economical. Its use in the pharmaceutical field is quite wide. It is used as a gelling agent, thickener, film forming agent, and volume enhancer by binding water. It has been used for the prevention of soft tissue and epidural scar adhesion after biosurgery. Sanino et al. suggested the use of gels containing CMC in the treatment of edema due to its water absorption property [12].

$\mathrm{N}$-Vinylpyrrolidone is a product of Reppe's modern acetylene chemistry studies. The first polymerization product of $\mathrm{N}$-vinylpyrrolidone is polyvinylpyrrolidone. Today, PVP has a versatile and wide range of pharmaceutical uses. Soluble PVP is obtained by free radical polymerization of vinylpyrrolidone in water or 2-vinylpyrrolidone [13]. PVP is a biocompatible, synthetic polymer and has been used as an additive for biomaterials or pharmaceutical ingredients for many years [14]. With the effect of different stimuli (radiation, heat, pressure, chemicals), PVP is crosslinked and the hydrogel formation is gained. PVP hydrogels are transparent and highly biocompatible. There are many studies on the synthesis and characterization of PVP hydrogels. However, due to the low mechanical properties and swelling capacities of these hydrogels, their applications are not widely spread. However, it has reported that mechanical properties of the PVP hydrogel increase in a good way when formulated with polysaccharides like carboxymethyl cellulose [15].

In this study, we synthesized different hydrogel formulations containing different polymers like laminarin, carboxymethyl cellulose and polyvinylpyrrolidone in order to be used in wound healing and investigated their in vitro properties.

\section{RESULTS}

\subsection{Scanning electron microscopy (SEM) analysis}

Figure 1 shows SEM images of Hydrogel-A (HA) hydrogel. Hydrogel has a highly porous structure that is homogeneously distributed. It is observed that the surface and pore walls of the hydrogel are rough.
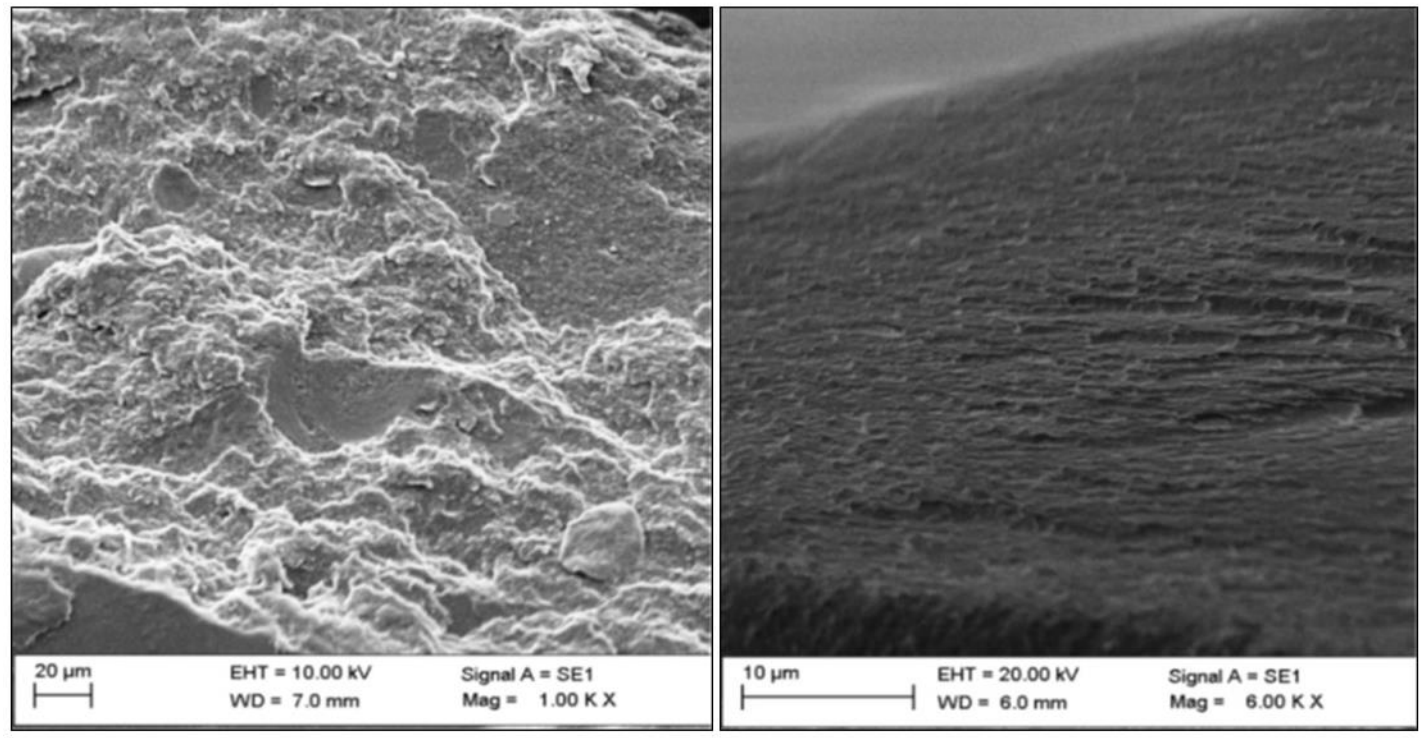

Figure 1. SEM images of HA hydrogel.

\subsection{Fourier-transform infrared spectroscopy (FTIR)}

Interactions of Laminarin, PVP, and CMC, which provide hydrogel formation, and the bonds formed were determined by FTIR analysis. Figure 2 shows the FTIR spectrum of laminarin, PVP, CMC polymers, and HA hydrogel. The absorption band located around $1656 \mathrm{~cm}^{-1}$ in the FTIR spectrum of PVP shows the stretching vibration of $\mathrm{C}=\mathrm{O}$ of the pyrrolidone group. The band at 2948 indicates asymmetric $\mathrm{CH}_{2}$ stretching. 
The bands at $1421 \mathrm{~cm}^{-1}$ and $1372 \mathrm{~cm}^{-1}$ correspond to $\mathrm{C}-\mathrm{H}$ bending from $\mathrm{CH}_{2}$ moieties. The band at $1283 \mathrm{~cm}^{-1}$ is related to $\mathrm{C}-\mathrm{N}$ bending vibration. The band at 1018 was identified as the $\mathrm{CH}_{2}$ rock. A large and broad band at $3400 \mathrm{~cm}^{-1}$ is due to O-H stretching [16,17]. In the FTIR spectrum of Na-CMC, the band at $\sim 3500 \mathrm{~cm}^{-1}$ corresponds to $\mathrm{O}-\mathrm{H}$ stretching vibrations. The band at $2895 \mathrm{~cm}^{-1}$ represents $\mathrm{C}-\mathrm{H}$ stretching vibration of $\mathrm{CH}_{2}$ and $\mathrm{CH}_{3}$ groups. The band at $1591 \mathrm{~cm}^{-1}$ confirms the presence of carboxylate group. The bands around 1413 and $1322 \mathrm{~cm}^{-1}$ indicate $-\mathrm{CH}_{2}$ scissoring and $-\mathrm{OH}$ bending vibrations, respectively. The band at $1023 \mathrm{~cm}^{-1}$ represents the $\mathrm{C}-\mathrm{O}-\mathrm{C}$ stretching vibration $[18,19]$. The FTIR spectrum of laminarin showed the characteristic broad band of O-H stretching vibration at $3363 \mathrm{~cm}^{-1}$ and the band of $\mathrm{C}-\mathrm{H}$ stretching vibration at $2916 \mathrm{~cm}^{-1}$. Laminarin exhibited anisomeric stretching which was identified by a band at around $1647 \mathrm{~cm}^{-1}$. The presence of carboxyl group was observed with a band near $1367 \mathrm{~cm}^{-1}$. The presence of CC and CO stretching vibrations in glycosidic bonds and pyranoid ring were predominate in the bands at $1071 \mathrm{~cm}^{-1}$ and $1032 \mathrm{~cm}^{-1}$ $[20,21]$. The FTIR spectrum of HA hydrogel shows the presence of hydroxyl group (-OH band) at $3322 \mathrm{~cm}^{-1}$. The band at $1640 \mathrm{~cm}^{-1}$ indicates the presence of carboxyl group. As shown in Figure 2a, the disappearance of the characteristic bands of PVA, Na-CMC and laminarin indicates that the three polymers interact with each other.
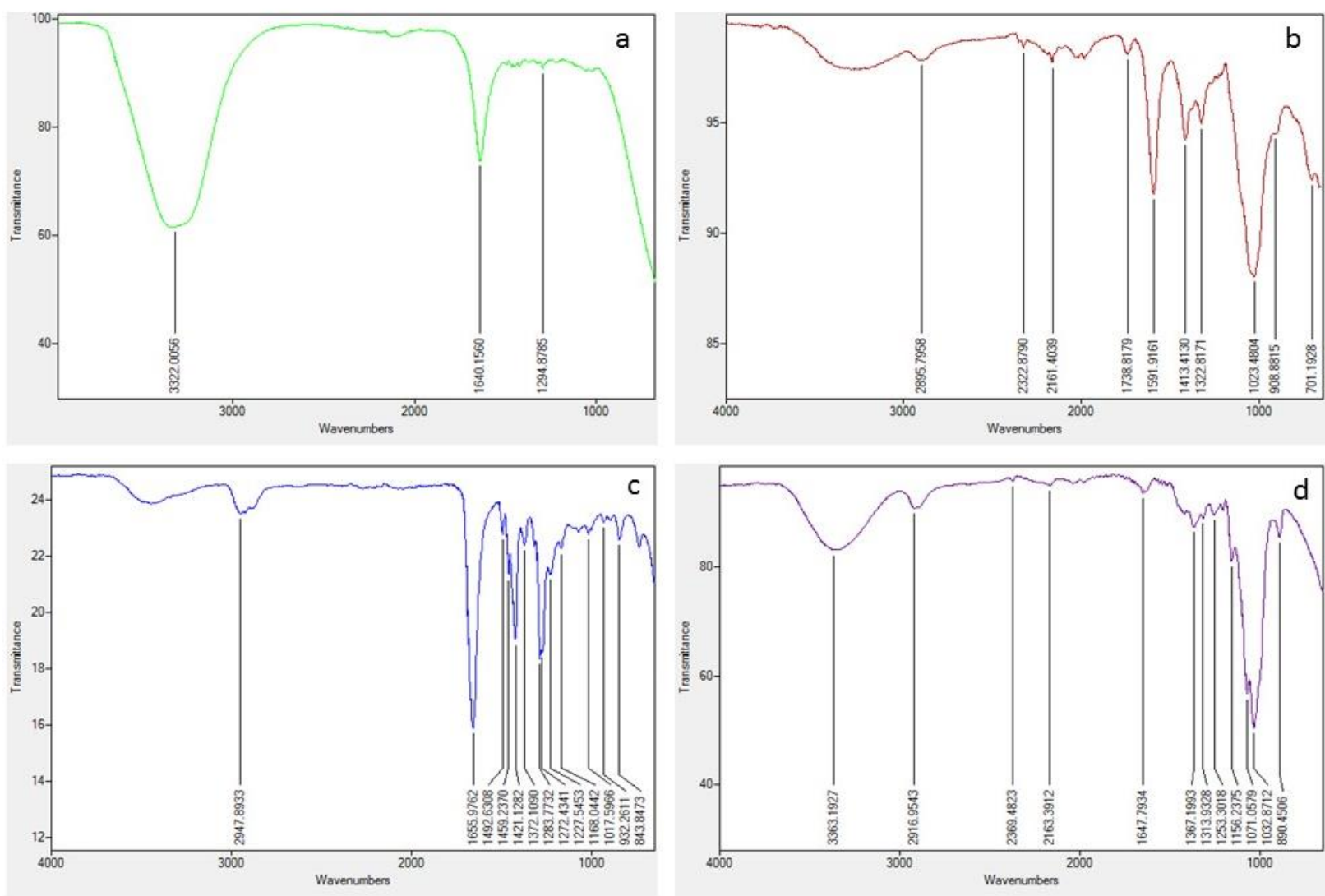

Figure 2. FTIR spectra of HA hydrogel (a), Na-CMC (b), PVP (c), and laminarin (d).

\subsection{Rheology of hydrogels}

Viscosity measurements were performed to examine the effect of polymer content on the viscosity of hydrogels and the results are shown in Table 1. The viscosity values of hydrogels ranged between 1689.3 and $24680 \mathrm{cPs}$. When HA3 and HB3 hydrogels were compared, it was seen that the molecular weight of PVP affected the viscosity. The use of higher molecular weight PVP in HB hydrogels increased the viscosity. According to the viscosity values of HA and HB hydrogels, when the laminarin concentration was kept constant, the change in Na-CMC and PVP concentrations affected the viscosity. It was seen that the viscosity increased when the concentration of Na-CMC increased. On the other hand, in HC hydrogels, the change in the laminarin concentration did not change the viscosity significantly. 
Table 1. Viscosity values of the hydrogels $(n=3)$.

\begin{tabular}{cc}
\hline Hydrogel & Viscosity $(\mathrm{cP} \pm \mathrm{SD})$ \\
\hline HA-1 & $1689.3 \pm 186.2$ \\
HA-2 & $4189.3 \pm 34.9$ \\
HA-3 & $4733.3 \pm 41.6$ \\
HB-1 & $5192.7 \pm 15.5$ \\
HB-2 & $8356.7 \pm 15.3$ \\
HB-3 & $24630 \pm 26.5$ \\
HC-1 & $24652.7 \pm 15.5$ \\
HC-2 & $24686.7 \pm 15.3$ \\
HC-3 & $24680 \pm 26.5$ \\
\hline
\end{tabular}

\subsection{Water absorption capacity of hydrogels}

The water absorption capacities of the prepared hydrogels were examined at different time intervals and the results are shown in Figure 3. While HA hydrogels have the highest water absorption capacity, the hydrogels with the lowest swelling rate are HB1 and HB2. This shows that increasing the molecular weight of PVP decreases the swelling rate of the hydrogels. Increasing Na-CMC concentrations in HA and $\mathrm{HB}$ hydrogels increased water absorption capacity. The increase of laminarin concentration in HC1, HC2, and HC3 hydrogels did not affect the swelling rate.
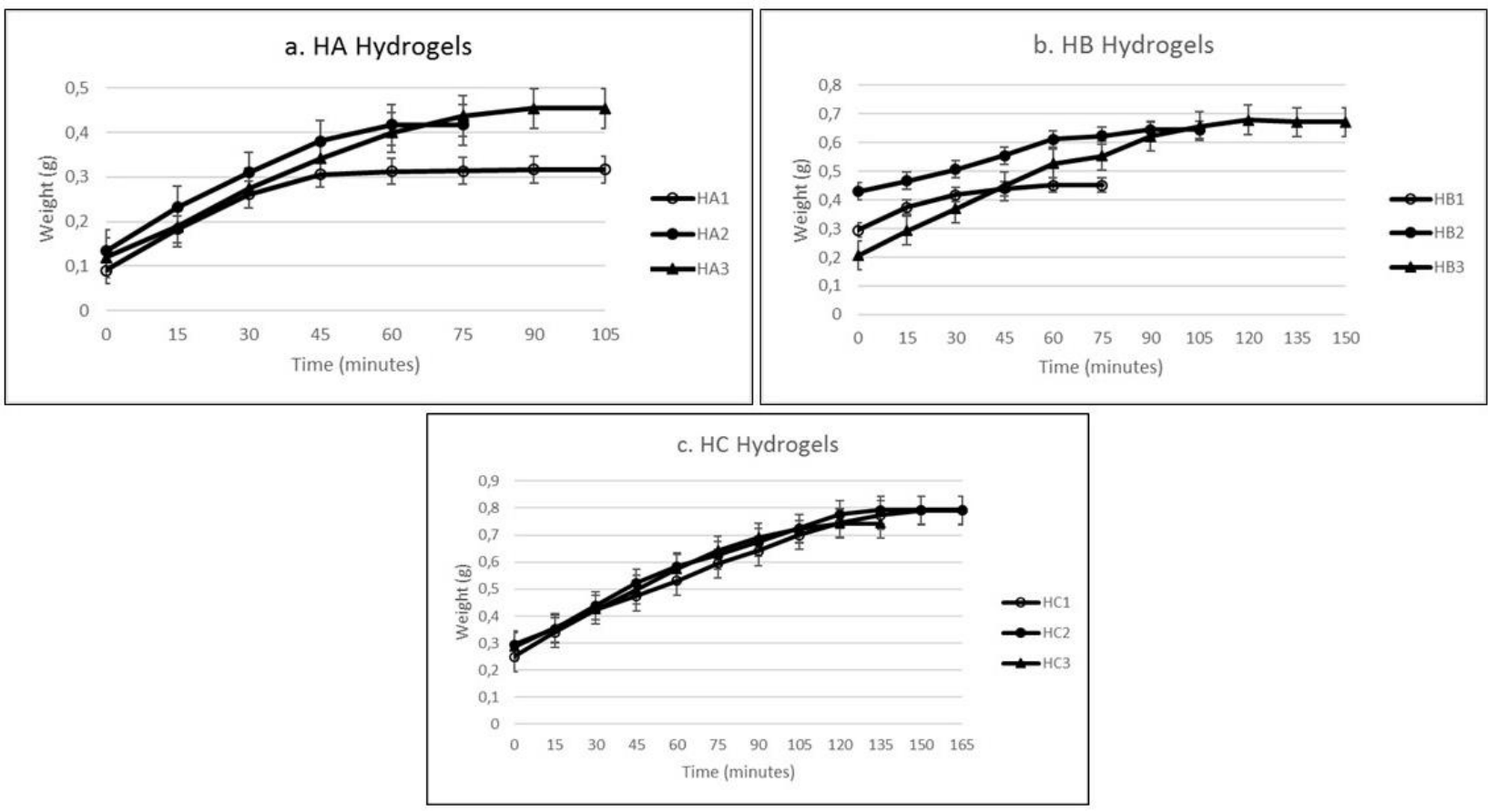

Figure 3. The weight increase of hydrogels versus time. a. HA hydrogels, b. HB hydrogels and c. HC hydrogels.

\subsection{Mechanical properties of hydrogels}

Hydrogels were tested in a Texture Analyzer to observe the effect of polymer content on the mechanical properties of hydrogels. The hardness, adhesiveness, cohesiveness, and elasticity values of hydrogels are shown in Table 2. It is seen that the hardness, adhesiveness, and cohesiveness values of HB hydrogels are higher than that of HA hydrogels. The increase in the molecular weight of PVP and the concentration of Na-CMC improved the mechanical properties of HA and HB hydrogels. However, the elasticity decreased on the contrary. The increase in the concentration of laminarin in HC hydrogels did not affect the hardness, adhesiveness, cohesiveness, and elasticity. 
Table 2. Mechanical properties of the hydrogels $(n=3)$.

\begin{tabular}{|c|c|c|c|c|}
\hline Hydrogels & $\begin{array}{l}\text { Hardness } \\
(\mathrm{Pa} \pm \mathrm{SD})\end{array}$ & $\begin{array}{l}\text { Adhesiveness } \\
\qquad\left(\mathrm{J} / \mathrm{m}^{2} \pm \mathrm{SD}\right)\end{array}$ & $\begin{array}{l}\text { Cohesiveness } \\
\qquad\left(\mathrm{J} / \mathrm{m}^{2} \pm \mathrm{SD}\right)\end{array}$ & $\begin{array}{l}\text { Elasticity } \\
(\mathrm{Pa} \pm \mathrm{SD})\end{array}$ \\
\hline HA1 & $0.033 \pm 0.000$ & 0 & 0 & 0 \\
\hline HA2 & $0.065 \pm 0.001$ & $1.428 \pm 1.228$ & $1.115 \pm 0,044$ & $2.868 \pm 0.105$ \\
\hline HA3 & $0.085 \pm 0.020$ & $1.420 \pm 1.056$ & $1.042 \pm 0.069$ & $2.725 \pm 0.173$ \\
\hline HB1 & $0.039 \pm 0.009$ & $1.765 \pm 1.732$ & $1.030 \pm 0.118$ & $2.096 \pm 0.940$ \\
\hline HB2 & $0.073 \pm 0.005$ & $16.597 \pm 3.959$ & $0.927 \pm 0.019$ & $0.990 \pm 0.014$ \\
\hline HB3 & $0.128 \pm 0.005$ & $24.611 \pm 1.906$ & $0.946 \pm 0.007$ & $0.991 \pm 0.006$ \\
\hline HC1 & $0.137 \pm 0.013$ & $15.440 \pm 4.126$ & $0.932 \pm 0.013$ & $1.131 \pm 0.225$ \\
\hline HC2 & $0.120 \pm 0.006$ & $16.883 \pm 1.461$ & $0.937 \pm 0.003$ & $1.003 \pm 0.006$ \\
\hline HC3 & $0.122 \pm 0.010$ & $16.815 \pm 4.237$ & $0.934 \pm 0.007$ & $1.049 \pm 0.043$ \\
\hline
\end{tabular}

\subsection{Bioadhesion of hydrogels}

The results regarding the bioadhesion properties of hydrogels are given in Table 3. It was seen that the bioadhesion values increased in HA, HB, and HC hydrogels, respectively. The increase in molecular weight of PVP and concentration of Na-CMC increased bioadhesion values. The highest bioadhesion value was seen in $\mathrm{HC} 1$ among HC hydrogels and HC1 had the lowest concentration of laminarin. Bioadhesion values of HC2 and HC3 hydrogels were found to be close to each other.

Table 3. Bioadhesion values of hydrogels $(n=3)$.

\begin{tabular}{cc}
\hline Hydrogels & Bioadhesion $\left(\mathrm{mJ} / \mathrm{cm}^{2} \pm\right.$ SD) \\
\hline HA1 & $0.070 \pm 0.060$ \\
HA2 & $0.059 \pm 0.009$ \\
HA3 & $0.265 \pm 0.053$ \\
HB1 & $0.075 \pm 0.031$ \\
HB2 & $0.389 \pm 0.057$ \\
HB3 & $0.542 \pm 0.048$ \\
HC1 & $0.826 \pm 0.050$ \\
HC2 & $0.628 \pm 0.066$ \\
HC3 & $0.604 \pm 0.117$
\end{tabular}

\section{DISCUSSION}

Hydrogels have an important place in the biomedical field due to their high water absorption capacity, soft structure, flexibility, and biocompatibility. Hydrogels provide great advantages in biomedical applications due to their resemblance to living tissue [22]. Hydrogels are widely used in various wounds to remove dead tissue [23]. Hydrogels are capable of absorbing moisture in a leaky wound and delivering moisture to dehydrated skin [24]. Hydrogels prepared with semi-synthetic polymers show many advantages over other topically applied systems in wound treatment due to their biocompatibility, minimal toxicity, and immunogenicity $[6,25]$.

Laminarin is a storage polysaccharide derived from brown algae [8]. Laminarin has been reported to have biological activities such as immunomodulatory, anti-inflammatory, antiviral, anti-tumoral, antithrombotic, anti-coagulant, and antioxidant [26]. In this study, PVP-CMC-Na hydrogels containing laminarin were prepared and the mechanical properties, water holding capacity, FTIR spectrum, and surface morphology of hydrogels were investigated. 
According to FTIR analysis, it was seen with the specific bands that CMC-Na and PVP were bound to the laminarin. The viscosity values of hydrogels prepared at different polymer concentrations varied between 1689.3 and $24680 \mathrm{cPs}$ (Table 2). The viscosity of hydrogels increased in direct proportion to the polymer concentration. The most important feature of CMC is providing viscosity. It is known that CMC is used as a gelling agent, thickener, film-forming agent, and volume enhancer by binding water [27].

The water absorption capacity of hydrogels versus time has been determined. It was observed that the swelling values of all hydrogels increased over time. While the highest water holding capacity was seen in HA hydrogels, the lowest water holding capacity was seen in HB hydrogels using high molecular weight PVP. PVP hydrogels are reported to have low mechanical properties and swelling capacity [15]. The increase of Na-CMC concentration in HA and HB hydrogels increased the water absorption capacity. Sannino et al, suggested the use of gels containing CMC due to their water absorption property in the treatment of edema [12].

Hydrogels have been evaluated for their hardness, elasticity, adhesion, and cohesion properties. Accordingly, HC hydrogels were found to be harder than HA and HB hydrogels. It was observed that the least hardness hydrogels were HA. Accordingly, it was observed that there was a directly proportional relationship between the polymer concentration and the hardness of the hydrogels. When hydrogels were evaluated in terms of adhesion, it was seen that HC hydrogels had the highest adhesion and HA hydrogels had the lowest adhesion. In terms of cohesion properties, it was observed that HB hydrogels showed higher cohesiveness than other hydrogels, and HA hydrogels showed lower cohesiveness than other hydrogels. When hydrogels are evaluated in terms of elasticity, HA is the most elastic hydrogel, while the least elastic hydrogel is HC hydrogel. When the mechanical properties of hydrogels are examined; It has been observed that the hardness, adhesion, and cohesion properties of hydrogels using high molecular weight PVP are better than hydrogels with low molecular weight PVP. It has been observed that the mechanical properties of hydrogels prepared with PVP and CMC positively improved [15, 28].

When the bioadhesion properties of hydrogels were examined, it was seen that as the viscosity increased, the bioadhesion property increased, and accordingly, HC hydrogels had the highest bioadhesion property. It was observed that the bioadhesion property increased in hydrogels containing high molecular weight PVP.

\section{CONCLUSION}

Many hydrogels have been used successfully in the treatment of wounds and burns, but since there is no hydrogel formulation prepared with laminarin so far, optimum formulations were tried to be developed using laminarin, $\mathrm{CMC}-\mathrm{Na}$, and PVP concentrations as formulation variables in this study. Hydrogels were successfully obtained at the specified concentrations. It has been determined that hydrogels using high molecular weight PVP have better mechanical properties, bioadhesion properties, and water absorption capacity.

\section{MATERIALS AND METHODS}

\subsection{Materials}

Low and medium molecular weight carboxymethylcellulose sodium salt, low and medium molecular weight polyvinylpyrrolidone and laminarin were purchased from Sigma (USA), Low molecular weight polyvinylpyrrolidone was purchased from BASF (Germany) and benzyl alcohol was purchased from Doğa İlaç (Turkey). All chemicals were of molecular grade.

\subsection{Preparation of laminarin containing hydrogels}

Different amount of laminarin was dissolved in water, then sodium carboxymethyl cellulose (Na$\mathrm{CMC}$ ) with different molecular weight was added to the laminarin solution and mixed in a magnetic stirrer until dissolved. After the Na-CMC was completely dissolved, polyvinylpyrrolidone (PVP) was added and mixed in a magnetic stirrer at $40^{\circ} \mathrm{C}$ at $400-500 \mathrm{rpm}$ until a homogeneous solution was obtained. The polymer mixture was left overnight at room temperature to allow the solution to gel. Hydrogels were kept in an ultrasonic water bath for 5 minutes in order to remove air bubbles formed during mixing and to provide a homogeneous appearance to the hydrogel, and they were stored in a glass bottle at $+4{ }^{\circ} \mathrm{C}$ until in vitro controls were carried out. Cross-linking process has been used to stabilize the hydrogels and increase their durability. For this purpose, gels prepared and kept at room temperature overnight were kept under ultraviolet light for 10 minutes. Hydrogel formulations are given in Table 4. 
Table 4. Laminarin containing PVP hydrogel formulations.

\begin{tabular}{cccccc}
\hline Codes & $\begin{array}{c}\text { Laminarin } \\
\text { conc. } \mathbf{( \% )}\end{array}$ & $\begin{array}{c}\text { PVP conc. } \\
\mathbf{( \% )}\end{array}$ & $\begin{array}{c}\text { Na-CMC conc. } \\
\mathbf{( \% )}\end{array}$ & $\begin{array}{c}\text { PVP mw } \\
\mathbf{( k D a )}\end{array}$ & $\begin{array}{c}\text { Na-CMC mw } \\
\text { (kDa) }\end{array}$ \\
\hline HA1 & 0.02 & 7 & 3 & 40 & 250 \\
HA2 & 0.02 & 6 & 4 & 40 & 250 \\
HA3 & 0.02 & 5 & 5 & 40 & 250 \\
HB1 & 0.02 & 7 & 3 & 360 & 250 \\
HB2 & 0.02 & 6 & 4 & 360 & 250 \\
HB3 & 0.02 & 5 & 5 & 360 & 250 \\
HC1 & 0.02 & 5 & 5 & 360 & 250 \\
HC2 & 0.04 & 5 & 5 & 360 & 250 \\
HC3 & 0.06 & 5 & 5 & 360 & 250 \\
\hline
\end{tabular}

\subsection{Scanning electron microscopy (SEM)}

In order to determine the surface morphology of hydrogels, samples taken from the surface of the lyophilized gels were coated with gold at a thickness of about $100 \AA$ under vacuum at a pressure of 0.01 mbar and examined under a scanning electron microscope (Jeol JSM 5200, Japan) at 100-1000 magnification and pictures of the samples were taken at 100-1000 magnification.

\subsection{Fourier-transform infrared spectroscopy (FTIR)}

In order to investigate the bonding between polymers in the prepared hydrogels, the gels were examined using FT-IR method. The infrared absorption spectrum of hydrogels was obtained using Shimadzu brand FT-IR with diamond crystals. The same study was done for laminarin, Na-CMC, and PVP.

\subsection{Viscosity of hydrogels}

After degassing the hydrogels in an ultrasonic bath, the viscosity of the gels at $25^{\circ} \mathrm{C}$ was measured by using Brookfield DV II + model viscometer. While making measurements, each sample was run at the appropriate rpm speed. In addition, the rheology of gels was studied. Tests were repeated 3 times for each formulation.

\subsection{Water absorption capacity of the hydrogels}

$1.0 \mathrm{~g}$ sample of the hydrogel whose swelling capacity will be measured was weighed and lyophilized. Lyophilized gels were placed in a $5.0 \mathrm{~cm}$ diameter petri dish. Then, $1 \mathrm{ml}$ of PBS pH 7.4 was added to the petri dish, which was tared with the gel, at intervals of 15 minutes, and when the gel was saturated, the excess liquid was removed from the environment and the tared petri dish was weighed again. The experiment was continued until the hydrogel reached constant weight, and water absorption ratio of hydrogels $(\mathrm{H} \%)$ was calculated with equation $\left[\left(\mathrm{AH}_{\mathrm{n}}-\mathrm{AH}_{0}\right) / \mathrm{AH}_{0}\right) \times 100$. Values were average of three measurements.

\subsection{Mechanical properties of hydrogels}

The mechanical properties of hydrogels were determined by TA.XT2 Plus Texture Analyzer. Before starting the test, the hydrogels were kept in an ultrasonic bath for 30 minutes to remove air bubbles. After the gels were brought to $37^{\circ} \mathrm{C}$, the probe of the device was dipped into the gel at a speed of $2 \mathrm{~mm} / \mathrm{sec}$ by 15 $\mathrm{mm}$ and withdrawn to the surface of the gel, after waiting for 15 seconds, the probe was dipped into the gel a second time and the test was completed. By using the force-time curve obtained, the hardness, adhesiveness, cohesiveness and elasticity values of the gels were calculated. The test was repeated three times for each formulation and the values were averaged.

\subsection{Bioadhesiveness of hydrogels}

The adhesion strength of the hydrogel to the skin was determined in the texture analyzer using a chicken skin model. Chicken skins taken immediately after slaughter were completely freed from their feathers and fat layer and prepared so that the outer part of the skin was smooth. Before starting the experiment, the skin was brought to $37^{\circ} \mathrm{C}$ and a $2.5 \mathrm{~cm}$ diameter section was taken from the heated skin 
samples and placed on the probe of the device using double-sided tape in a stretched manner. After the hydrogels to be tested were poured into the tray of the texture device properly in a way that there would be no air gaps in $34.8 \mathrm{~mm}$ diameter petri dishes, the experiment was performed using the test parameters given below. With the start of the experiment, the probe carrying the skin was brought down at a constant speed and brought into contact with the gel surface, and after keeping it in contact for 120 seconds, the probe was pulled upwards at the same constant speed. Bioadhesion was calculated from the force-distance curve obtained. The area under the force-distance curve $\left(\mathrm{AUC}_{1-2}\right)$ gives the bioadhesion work, its unit is $\mathrm{mJ}(\mathrm{N} \times$ $\mathrm{mm}$ ) and the following formula is used to calculate the bioadhesion work per $1 \mathrm{~cm}^{2}$. The test was repeated 3 times for each formulation and the average of the values was calculated.

Acknowledgements: This study was supported by the Commission of Marmara University Scientific Research Project BAPKO (SAG-C-YLP-280214-0038).

Author contributions: Concept - S.T.E., A.D.S.; Design - S.T.E, A.D.S.; Supervision - A.D.S., S.T.E.; Resources A.D.S.; Materials - S.T.E, A.D.S.; Data Collection and/or Processing - S.T.E, A.D.S.; Analysis and/or Interpretation S.T.E, A.D.S., B.C., C.E.A.; Literature Search - S.T.E., B.C., C.E.A.; Writing - S.T.E., B.C., C.E.A..; Critical Reviews S.T.E, A.D.S., B.C., C.E.A

Conflict of interest statement: The authors declared no conflict of interest.

\section{REFERENCES}

[1] Baroli B. Hydrogels for Tissue Engineering and Delivery of Tissue-Inducing Substances. J Pharm Sci. 2007; 96(9): 2197-2223. [CrossRef]

[2] Mahinroosta M, Farsangi ZJ, Allahverdi A, Shakoori Z. Hydrogels as intelligent materials: a brief review of synthesis, properties and applications. Materials Today Chemistry. 2018; 8: 42-55. [CrossRef]

[3] Abandansari HS, Aghaghafari E, Nabid MR, Niknejad H. Preparation of injectable and thermoresponsive hydrogel based on penta-block copolymer with improved sol stability and mechanical properties. Polymer. 2013; 54(4): 13291340. [CrossRef]

[4] He F, Zhang Y, Li J, Liu S, Chi Z, Xu J. Preparation and properties of multi-responsive semi-IPN hydrogel modified magnetic nanoparticles as drug carrier. J Control Release. 2011; 152(1): e119-e121. [CrossRef]

[5] Epstein-Barash H, Stefanescu CF, Kohane DS. An in situ cross-linking hybrid hydrogel for controlled release of proteins. Acta Biomaterialia. 2012; 8(5): 1703-1709. [CrossRef]

[6] Costache MC, Qu H, Ducheyne P, Devore DI. Polymer-xerogel composites for controlled release wound dressings. Biomaterials. 2010; 31(24): 6336-6343. [CrossRef]

[7] Miao HQ, Elkin M, Aingorn E, Ishai-Michaeli R, Stein CA, Vlodavsky I. Inhibition of heparanase activity and tumor metastasis by laminarin sulfate and synthetic phosphorothioate oligodeoxynucleotides. Int J Cancer. 1999; 83(3): 424-431. [CrossRef]

[8] O'Sullivan L, Murphy B, McLoughlin P, Duggan P, Lawlor PG, Hughes H, Gardiner GE. Prebiotics from marine macroalgae for human and animal health applications. Mar Drugs. 2010; 8(7): 2038-2064. [CrossRef]

[9] Choi Ji, Kim HJ, Lee JW. Structural feature and antioxidant activity of low molecular weight laminarin degraded by gamma irradiation. Food Chem. 2011; 129(2): 520-523. [CrossRef]

[10] Wasser SP. Medicinal mushrooms as a source of antitumor and immunomodulating polysaccharides. Appl Microbiol Biotechnol. 2002; 60(3): 258-274. [CrossRef]

[11] Yadav M, Rhee KY, Jung IH, Park SJ. Eco-friendly synthesis, characterization and properties of a sodium carboxymethyl cellulose/graphene oxide nanocomposite film. Cellulose. 2013; 20: 687-698. [CrossRef]

[12] Sannino A, Madaghiele M, Conversano F, Mele G, Maffezzoli A, Netti P, Nicolais L Cellulose derivative-hyaluronic acid-based microporous hydrogels cross-linked through divinyl sulfone (DVS) to modulate equilibrium sorption capacity and network stability. Biomacromolecules. 2004; 5(1): 92-96. [CrossRef]

[13] Raith K, Kühn AV, Rosche F, Wolf R, Neubert RH Characterization of Povidone Products by Means of ${ }^{13}$ C-NMR, MALDI-TOF, and Electrospray Mass Spectrometry. Pharm Res. 2002; 19(4): 556-560. [CrossRef]

[14] Zhao L, Xu L, Mitomo H, Yoshii F. Synthesis of $\mathrm{pH}$-sensitive PVP/CM-chitosan hydrogels with improved surface property by irradiation. Carbohydr Polym. 2006; 64(3): 473-480. [CrossRef] 
[15] Roy N, Saha N, Kitano T, Saha P. Novel hydrogels of PVP-CMC and their swelling effect on viscoelastic properties. J Appl Polym Sci 2010; 117(3): 1703-1710. [CrossRef]

[16] Kamaruddin, Edikresnha D, Sriyanti I, Munir MM, Khairurrijal. Synthesis of Polyvinylpyrrolidone (PVP)-Green Tea Extract Composite Nanostructures using Electrohydrodynamic Spraying Technique. IOP Conf. Ser.: Mater. Sci. Eng. 2017; 202 (012043):1-7. [CrossRef]

[17] Safo A, Werheid M, Dosche C, Oezaslan M. The role of polyvinylpyrrolidone (PVP) as a capping and structuredirecting agent in the formation of Pt nanocubes. Nanoscale Adv. 2019; 1: 3095-3106. [CrossRef]

[18] Sunardi, Febriani NM, Junaidi AB. Preparation of carboxymethyl cellulose produced from purun tikus (Eleocharis dulcis). AIP Conf Proc. 2017; 1868 (020008): 1-8. [CrossRef]

[19] Kadry G. Comparison between gelatin/carboxymethyl cellulose and gelatin/ carboxymethyl nanocellulose in tramadol drug loaded capsule. Heliyon. 2019; 5 (9): e02404 1-10. [CrossRef]

[20] Ji CF, Ji YB, Meng DY. Sulfated modification and anti-tumor activity of laminarin. Exp Ther Med. 2013; 6(5): 12591264. [CrossRef]

[21] Rajauria G, Ravindran R, Garcia-Vaquero M, Rai DK, Sweeney T, O'Doherty J. Molecular characteristics and antioxidant activity of laminarin extracted from the seaweed species Laminaria hyperborea, using hydrothermalassisted extraction and a multi-step purification procedure. Food Hydrocoll. 2021; 112: 106332 1-10. [CrossRef]

[22] Caló E, Khutoryanskiy VV. Biomedical applications of hydrogels: a review of patents and commercial products. Eur Polym J. 2015; 65: 252-267. [CrossRef]

[23] Lay-Flurrie K. The properties of hydrogel dressings and their impact on wound healing. Prof Nurse. 2004; 19(5): 269-273.

[24] Thomas S, Hay P. Fluid handling properties of hydrogel dressings. Ostomy Wound Manage. 1995; 41(3), 54-6, 58-9.

[25] Fansler RF, Taheri P, Cullinane C, Sabates B, Flint LM. Polypropylene mesh closure of the complicated abdominal wound. Am J Surg. 1995; 170(1): 15-18. [CrossRef]

[26] Moroney NC, O'Grady MN, Lordan S, Stanton C, Kerry JP. Seaweed Polysaccharides (Laminarin and Fucoidan) as Functional Ingredients in Pork Meat: An Evaluation of Anti-Oxidative Potential, Thermal Stability and Bioaccessibility. Mar Drugs. 2015; 13(4): 2447-2464. [CrossRef]

[27] Kamel S, Ali N, Jahangir K, Shah S, El-Gendy A. Pharmaceutical significance of cellulose: a review. Express Polym Lett. 2008; 2(11): 758-778. [CrossRef]

[28] Lü S, Liu M, Ni B, Gao C. A novel pH-and thermo-sensitive PVP/CMC semi-IPN hydrogel: Swelling, phase behavior, and drug release study. J Polym Sci B Polym Phys. 2010; 48(15): 1749-1756. [CrossRef] 